\title{
Formation of layered fracture and outburst during gas hydrate dissociation
}

\author{
X.H. Zhang ${ }^{\text {a,* }}$, X.B. Lu ${ }^{\text {a }}$, Q.P. Li ${ }^{\text {b }}$ \\ a Laboratory for Hydrodynamics and Ocean Engineering, Institute of Mechanics, Chinese Academy of Sciences, Beijing 100190, China \\ ${ }^{\mathrm{b}}$ Research Centre, China Ocean Oil Co., Beijing 100027, China
}

\section{A R T I C L E I N F O}

\section{Article history:}

Received 18 June 2010

Accepted 10 January 2011

Available online 24 January 2011

\section{Keywords:}

hydrate dissociation

excess pore pressure

dissociation zone

layered fracture

outburst

\begin{abstract}
A B S T R A C T
Hydrate dissociation in marine sediments may cause large hazards. Two types of new hazard phenomena, outburst and layered fracture, are observed in laboratory experiments and the initiation mechanism is discussed. Experiments are carried out in a two-dimensional rectangular box and a one-dimensional cylinder, respectively. It is shown that layered fracture and outburst can appear after hydrate dissociation and are related closely to dissociation speed, permeability, strength of hydrate-bearing sediment and over-layered stratum. Outburst often occurs at low permeability, high strength of over layered stratum and high pore pressure, while layered fracture is just on the contrary.
\end{abstract}

(C) 2011 Elsevier B.V. All rights reserved.

\section{Introduction}

Natural gas hydrate is a crystalline solid composed mainly of methane gas molecules and water molecules, and is stabilized in conditions of high pressure and low temperature. Natural gas hydrate is extensively distributed in sediments of oceans, continental margins and deep lakes and is regarded as a potential energy resource (Gilles et al., 1999; Hisashi et al., 2002; Riedel et al., 2006; Sloan, 1998).

Hydrate-bearing sediments may destabilize spontaneously as part of a geological process, unavoidably during petroleum drilling/production operations (Briaud and Chaouch, 1997), or intentionally as part of gas extraction from the hydrate itself, which will directly change the strength of the hydrate-bearing sediments. Meanwhile the released gas can increase the pore pressure (Kwon et al., 2008; Sultan et al., 2004b; Xu and Germanovich, 2006; Xu and Germanovich, 2007). Generally, $1 \mathrm{~m}^{3}$ of methane gas hydrate may release $164 \mathrm{~m}^{3}$ of methane gas and $0.8 \mathrm{~m}^{3}$ of water at $1 \mathrm{~atm}$ at normal temperature. When hydrate dissociation in hydrate-bearing sediments occurs without fluid flow, an excess pore pressure of more than $40 \mathrm{MPa}$ occurs under an initial condition of hydrate fraction 0.2 , temperature $6{ }^{\circ} \mathrm{C}$, pressure $4.9 \mathrm{MPa}$, and hydrate-bearing sediment stiffness $10^{10} \mathrm{~Pa}$, and the excess pore pressure increases with hydrate fraction and sediment stiffness. Then the large excess pore pressure will result in a strength decrease of the sediment if the released gas diffuses slowly. Accordingly, serious disasters may happen, such as destruction of ocean platforms, seabed, oil wells, and even gas blowouts (Bard et al., 1990; Dickens and Quinby-Hunt, 1994; Kwon et al., 2008; Milkov, 2000; Sultan et al., 2004b; Xu and Germanovich, 2006; Xu and

\footnotetext{
* Corresponding author.

E-mail address: zhangxuhui@imech.ac.cn (X.H. Zhang).
}

Germanovich, 2007). Some tried to explain the Bermuda mystery by gas plume due to the dissociation of gas hydrate (Gruy, 1998; Kvenvolden, 1998). The thermal conduction in hydrate-bearing sediments is studied (Briaud and Chaouch, 1997). It is shown that the hydrate dissociation front around a high temperature oil pipe with $1 \mathrm{~m}$ diameter can reach $20 \mathrm{~m}$ after $15 \mathrm{yr}$, and $30 \mathrm{~m}$ after $40 \mathrm{yr}$, which may cause instabilities of seafloor foundations. It is reported that the Storegga landslide on the Norwegian continental shelf, the largest landslide in the world with 2500-3200 $\mathrm{m}^{3}$ deposits brought away, was just caused by gas hydrate dissociation (Bouriak et al., 2000; Bugge et al., 1987; Sultan et al., 2004a). Hydrate dissociation is also thought to be the main reason once the being monitored slope at the US mid-Atlantic coast slides when sea water temperature rises continuously (Driscoll et al., 2000; Jung and Peter, 2004).

In fact, thermally induced evolution of sediment failure is a basic physical-chemical-mechanical process in the dissociation of gas hydratebearing sediment. Heat transfer leads to the weakening of the bed soil and the simultaneous establishment of a time varying stress field accompanied by seepage of fluids and deformation of the soil. As a consequence, ground failure could occur causing an engineering damage or/and environmental disaster. However, possible thermally induced evolution of sediment failure patterns and key parameters controlling failure are known little. Thermal dissociation of the hydrate in hydrate-bearing sediments is related with three temporal characteristic parameters: thermal conduction time $t_{c}^{*}=\rho C l^{2} / \lambda$, seepage time $t_{p}^{*}=\mu_{g} l^{2} / k_{g} p_{e}$, and time of elastic wave propagation $t_{e}^{*}=l / \sqrt{E / \rho}$, here, $\rho, C, l, \lambda, \mu_{g}, k_{g}, p_{e}$, and $E$ are density, specific heat, characteristic length, thermal conductivity, methane gas viscosity, gas permeability, pressure in phase equilibrium, and elastic modulus respectively. Their ratio is about $10^{9}: 10^{5}: 1$. That means the problem involves three independent processes, i.e. thermal conduction, seepage, and elastic wave propagation. Thus we first analyze the thermal 
conduction involving phase transition, and then the pressure distribution in sediment, and finally the failure of sediment due to redistribution of stresses (Zhang et al., 2010).

In this paper, laboratory experiments are designed to investigate the possible sediments failure and the patterns of sediment instability due to hydrate dissociation accompanied by the evolution of the temperaturepressure and hydrate dissociation front in hydrate-bearing sediments.

\section{Experiments of phase equilibrium after tetra-hydro-furan (THF) hydrate dissociation}

The physical and thermal properties of tetra-hydro-furan (THF) hydrate are close with that of methane gas hydrate, e.g., $\frac{\kappa_{T F H}}{\kappa_{M H}} \approx 0.5 \sim 1.6, \frac{\Delta H_{T F H}}{C_{T F H}} / \frac{\Delta H_{M H}}{C_{M H}} \approx 0.5 \sim 0.8, \frac{\chi_{T F H}}{\chi_{M H}} \approx 1.5, \frac{\rho_{T F H}}{\rho_{M H}} \approx 1.1$ (Table 1), here $\kappa, \Delta H, C, \chi$, and $\rho$ are thermal diffusivity, enthalpy of hydrate dissociation, specific heat, hydrate number, and density of hydrate respectively, and THF and $\mathrm{MH}$ stands for THF hydrate and methane hydrate respectively. Meanwhile, a large volume of THF deposit can be synthesized easier and safer and more economic relative to methane hydrate deposit, since THF is completely miscible with water in all proportions and form hydrate at one atmospheric pressure and an appropriate temperature (Jones et al., 2007; Tohidi et al., 2001). THF hydrate has a density $\left(0.94 \mathrm{~g} / \mathrm{cm}^{3}\right)$ comparable to methane hydrate $\left(0.91 \mathrm{~g} / \mathrm{cm}^{3}\right)$ (Koh, 2002). Hence THF deposits are adopted as a good surrogate for methane hydrate in all the experiments. Then phase equilibrium after tetra-hydro-furan (THF) hydrate dissociation is tested.

Experiments are carried out in a pressure cell (maximum pressure $20 \mathrm{MPa}$ ) with a size of diameter $75 \mathrm{~mm}$ and height $52 \mathrm{~mm}$, temperature sensor is placed in the middle of hydrate-bearing sediments, pressure gauge is linked to pressure tank through a small vessel with a size of diameter $4 \mathrm{~mm}$ and length $80 \mathrm{~mm}$, and when gas is released after hydrate dissociation, the pressure is measured.

In preparing samples, silty sand with a density of $1.6 \mathrm{~g} / \mathrm{cm}^{3}$ is first compacted to form the skeleton (Fig. 1) and then saturated by THF liquor with a mass fraction of $19 \%$. THF hydrate sediment is synthesized by laying the saturated sediment for 3-5 days under $-8{ }^{\circ} \mathrm{C}$.

Results show that the excess pore pressure evolution with temperature after hydrate dissociation in THF hydrate-bearing sediments is close to the theoretical value of THF saturated vapor pressure (Fig. 2).

\section{Experiments in organic glass box}

\subsection{Preparation of experiments}

Experiments are first carried out in an organic glass box with a size of length $\times$ height $\times$ width $=30 \mathrm{~cm} \times 50 \mathrm{~cm} \times 10 \mathrm{~cm}$ (Fig. 3). An immersion heater as heat source is horizontally placed (parallel to the short side of the box) $10 \mathrm{~cm}$ below the surface of the deposit. To heat the deposit by the heater cannot only fasten the dissociation process of hydrate, but also catch the main characteristics. The maximum output temperature of the heater is controlled by a temperature regulator.

Table 1

Comparison of thermal properties between tetra-hydro-furan hydrate and methane hydrate (Zhang et al., 2010).

\begin{tabular}{lll}
\hline Type of sediments & $\begin{array}{l}\text { THF } \\
\text { hydrate }\end{array}$ & MH \\
\cline { 1 - 1 } Thermal parameters & & $0.45-0.54$ \\
\hline Thermal conductivity $/ \mathrm{w} / \mathrm{m} / \mathrm{K}$ & 2.123 & $0.4-0.6$ \\
Specific heat $/ \mathrm{kJ} / \mathrm{kg} / \mathrm{K}$ & 997 & $1.6-2.7$ \\
Density $/ \mathrm{kg} / \mathrm{m}^{3}$ & 270 & 913 \\
Enthalpy $/ \mathrm{kJ} / \mathrm{kg}$ & & 429.66 \\
\hline
\end{tabular}

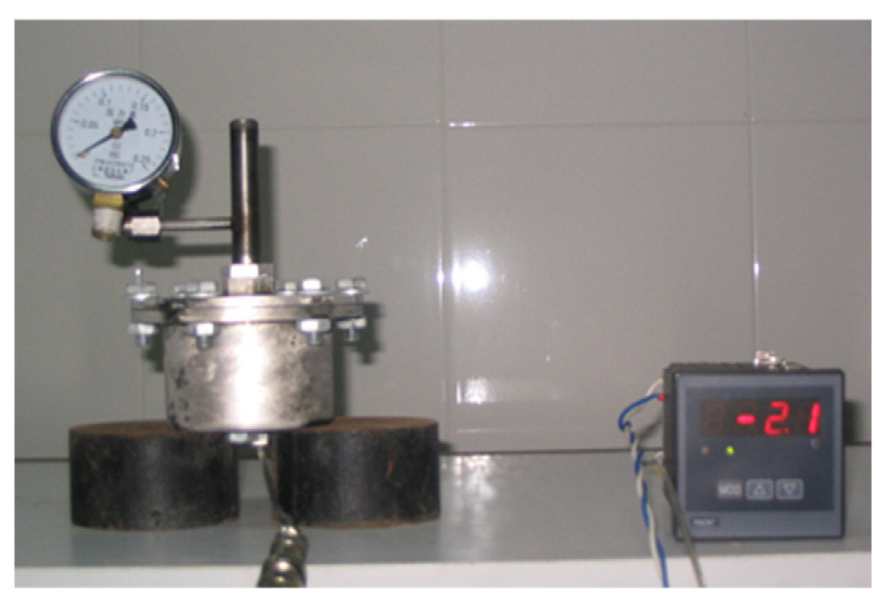

Fig. 1. Layout of model for THF hydrate phase equilibrium test.

In preparing the samples, silty sand with a density of $1.6 \mathrm{~g} / \mathrm{cm}^{3}$ is first compacted to form the skeleton (Fig. 4) and then saturated by THF liquor with a mass fraction of $19 \%$. THF hydrate deposit is synthesized by laying the saturated deposit for $3-5$ days under $-8{ }^{\circ} \mathrm{C}$. Two types of over cap, $5 \mathrm{~cm}$ silty sand layer and $5 \mathrm{~cm}$ hydrate deposit (HD), are set up respectively to investigate the effects of permeability and sidewall's friction. During experiments, the environmental temperature is kept at $-8{ }^{\circ} \mathrm{C}$.

\subsection{Results and analysis}

The gas hydrate deposit may be damaged in the form of outburst when hydrate dissociates fast. Three stages are identified to precede the failure: (1) the dissociation zone expands gradually till $30 \mathrm{~min}$ after heating. (2) The temperature and pore pressure state keeps for about $10 \mathrm{~min}$. (3) Outburst occurs immediately following sound emission and lasts for less than $10 \mathrm{~s}$ (Fig. 4).

Fig. 5 shows the development of temperature and pressure in 3 experiments (named as A, B and C). The conditions and main measured data are shown in Table 2. It can be seen that temperature increases fast in the first $4 \mathrm{~min}$. For example, in experiment B near the immersion heater rises fast to $120^{\circ} \mathrm{C}$ after about $4 \mathrm{~min}$ and then keeps the value till the occurrence of outburst. With the increase of temperature, the pore gas pressure increases fast also at the first stage and then decreases a little with the expansion of dissociation zone and the gas seepage. The gas pressure rises again when the dissociation zone does not expand anymore. The gas pressures are all equal to $0.1 \mathrm{MPa}$ just before the damage of deposit. The reason is that most water is concentrated on the front of the dissociation zone

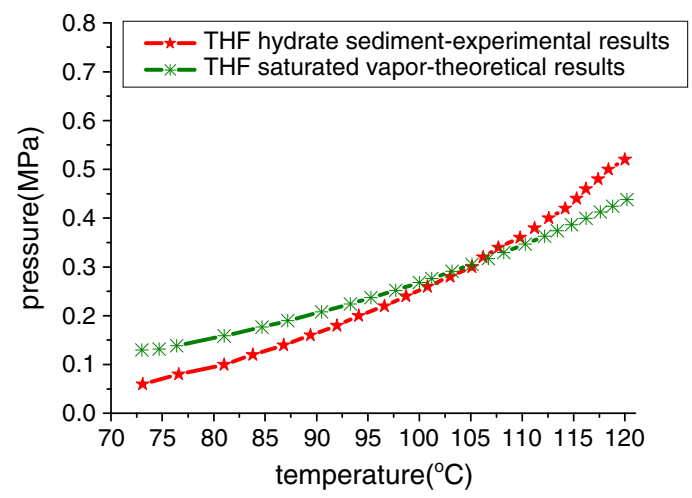

Fig. 2. Pressure evolution with temperature after THF hydrate dissociation in sediments. 


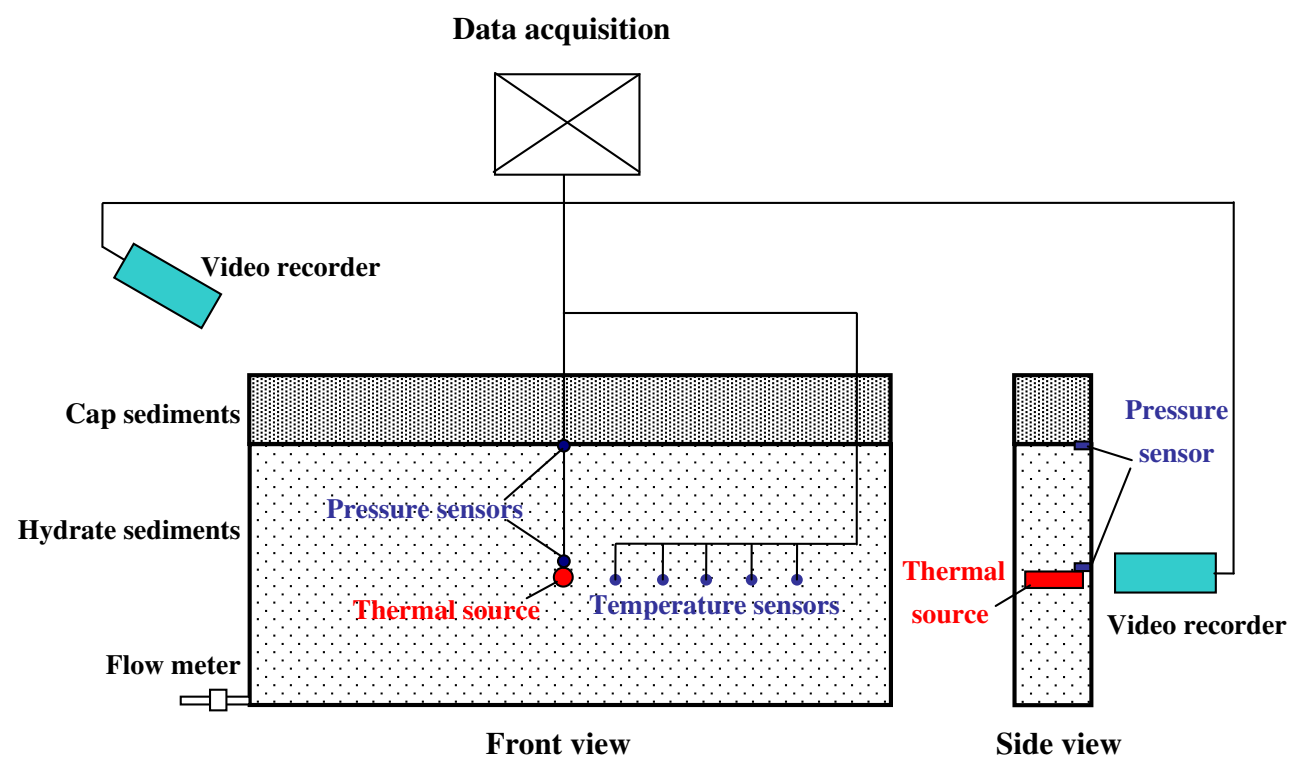

Fig. 3. Layout of two-dimensional model.

where temperature is low (near the phase balance point). Thus the gas pressure is only $0.1 \mathrm{MPa}$, a value near the vapor pressure under this temperature.

\section{A}

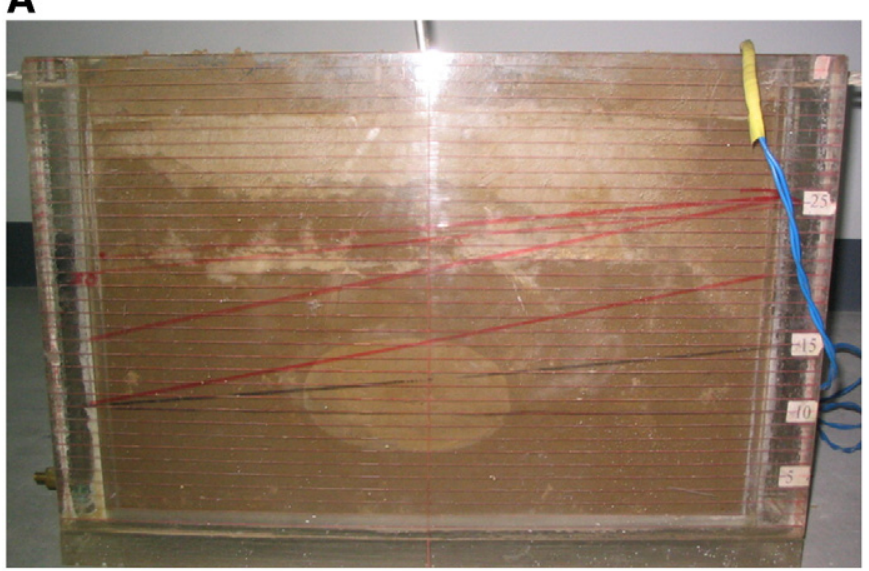

B

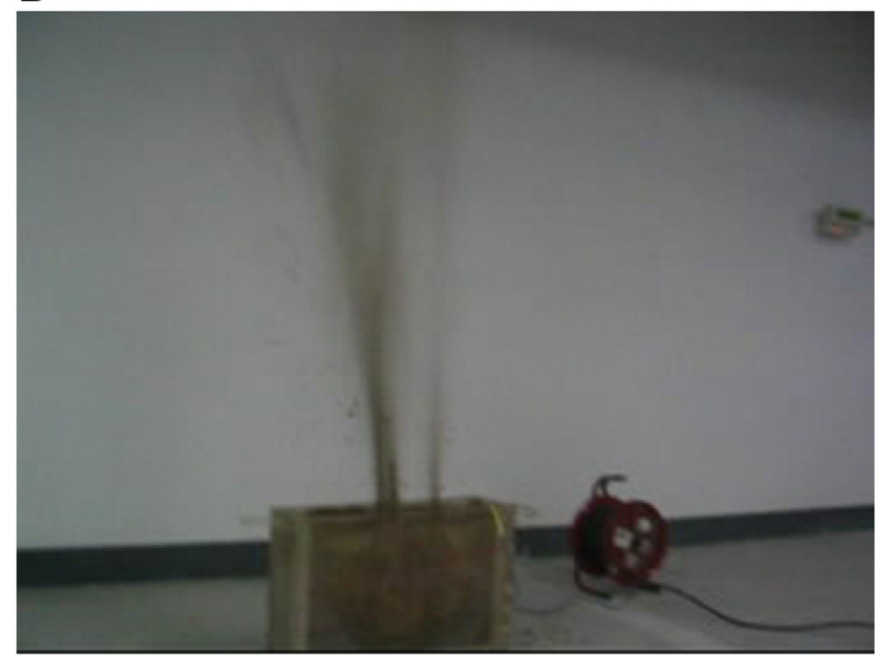

Fig. 4. Outburst in experiments: A. Expanding of the dissociation zone and B. Bursting of the hydrate sediments.
After opening of the deposit after experiments, the cave is just coincident with the dissociation zone. That means, the outburst material comes almost from the dissociation zone, where the soils must have been liquefied.

\section{Experiments in organic glass cylinder}

Except for in the above two dimensional box, experiments have also been done in an organic glass cylinder with a size of inner diameter $\times$ height $=10 \mathrm{~cm} \times 30 \mathrm{~cm}$, because in such a one dimensional
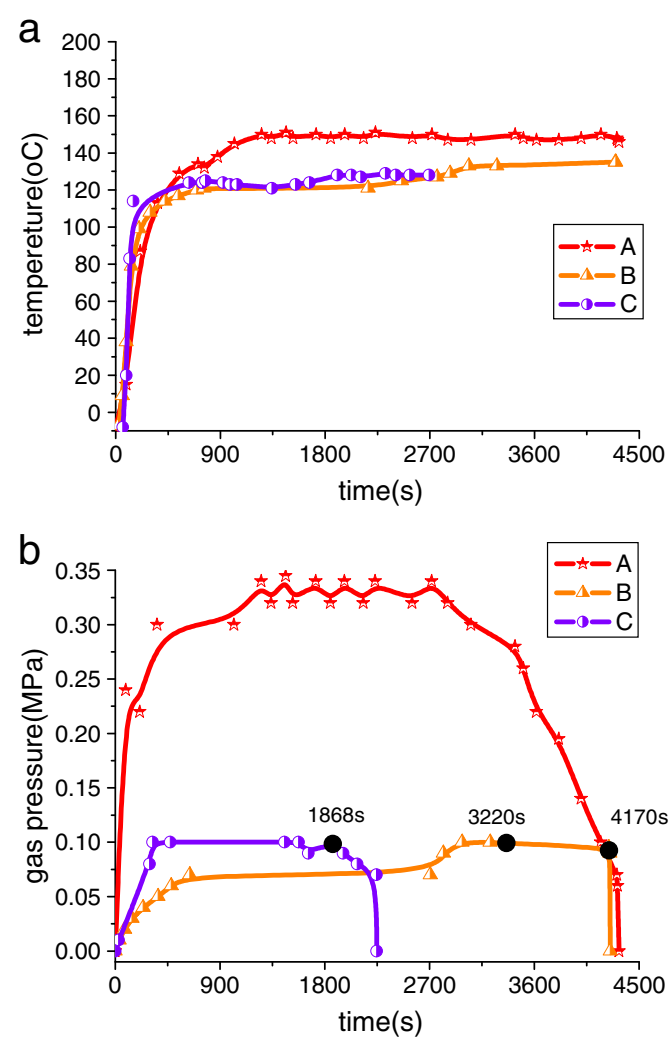

Fig. 5. Development of pressure-temperature: a. Development of temperature and b. Development of pressure. 
Table 2

Experimental parameters and measured data.

\begin{tabular}{lccc}
\hline No. & A & B & C \\
\hline Max. temperature $\left({ }^{\circ} \mathrm{C}\right)$ & 150 & 120 & 130 \\
Thickness of over cap $(\mathrm{cm})$ & 5 & 2 & 2 \\
Heating time (min) & 72.1 & 71.8 & 44.9 \\
Dissociation radius $(\mathrm{cm})$ & 10.8 & 9.75 & 9 \\
Pressure at outburst $(\mathrm{MPa})$ & 0.1 & 0.1 & 0.1 \\
\hline
\end{tabular}

model the conditions and measurements can be controlled more accurately. In this model, an immersion heater with power of $400 \mathrm{~W}$ and size of length $\times$ diameter $=12 \mathrm{~cm} \times 1 \mathrm{~cm}$ is vertically placed $10 \mathrm{~cm}$ below the lower boundary of the over cap (Fig. 6).

Fig. 7 shows the development of temperature and gas pressure in three experiments D, E and F. It is observed that layered fracture occurs in experiments $\mathrm{D}$ and $\mathrm{E}$, while outburst occurs in experiment $\mathrm{F}$.

In experiments $\mathrm{D}$ and $\mathrm{E}$, the temperature near the heat source rises fast to $115^{\circ} \mathrm{C}$ in the first 2 min of heating, and then keeps stable. With the expansion of the dissociation zone, gas percolation upwards while liquid THF and water stay at the lower part. During the rise of temperature, heat absorption during phase transition of THF and water gasification is balanced with the thermal provided by immersion heater. Thus the temperature keeps close to $100{ }^{\circ} \mathrm{C}$, the boiling point of water. Gas pressure in experiments D and $\mathrm{E}$ is lower than that in experiment $\mathrm{F}$ and layered fracture occurs because the over cap is a permeable soil layer with low strength (Fig. 8). Generally, there are two layered fractures, one at the interface between HD and over cap, and the other at the upper interface in the over cap. The main reason is that the percolation of dissociation-induced gas causes the sharp increase of pore pressure near the interface between HD and over cap since the interface is a weak place. The high excess pore pressure can cause the over cap to move upward when the pore pressure is larger than the total weight of the over cap and the friction between the over cap and the sidewall (boundary friction). Meanwhile, the gasified deposit in the dissociation zone settles gradually. With the expansion of dissociation zone, gas percolates to the upper part and damage the structure, so there occurs a layered fracture.

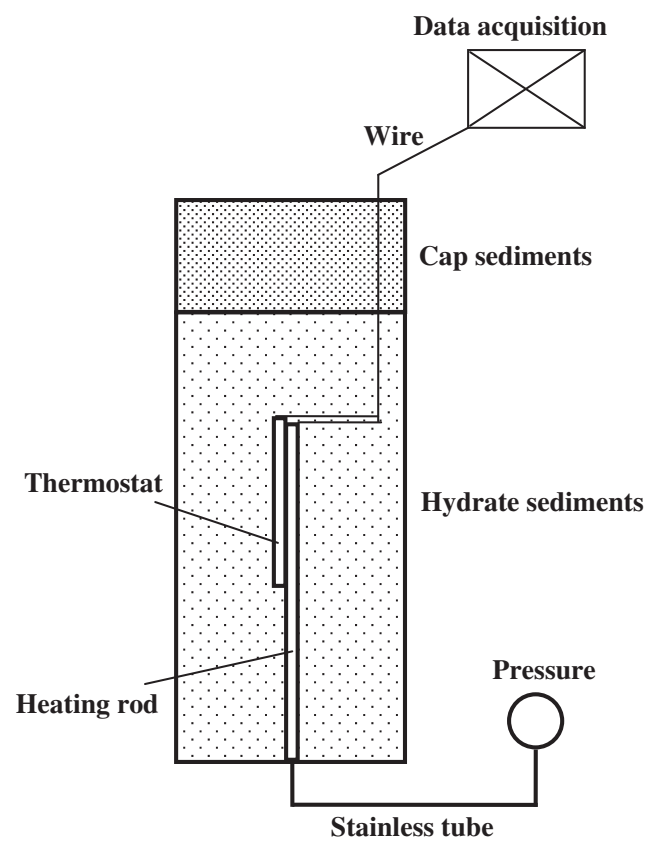

Fig. 6. Layout of one-dimensional model.

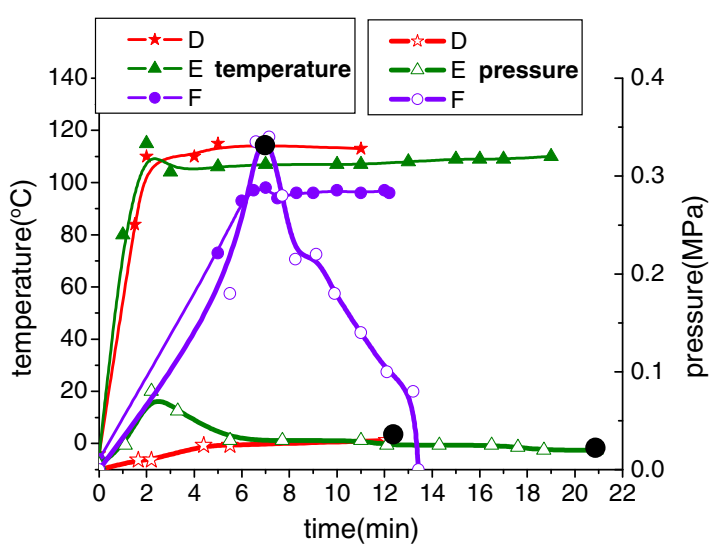

Fig. 7. Pressure-temperature evolution curve.

When the over cap is constituted of HD (experiment $\mathrm{F}$ ), the deposit outbursts accompanied by a loud whistle with temperature rising fast to about $100{ }^{\circ} \mathrm{C}$ within 4 min after heating and the maximum gas pressure rising to $0.3 \mathrm{MPa}$. There is no weak interface in the deposit because the whole sample is consisted of HD and so has large strength and low permeability. The friction between the deposit and the sidewall is measured $0.18 \mathrm{MPa}$. Since the weight of the over part is comparably small, the gas pressure may jack up the over cap and trigger the outburst of gasified deposit only when it surpasses the friction (Fig. 9). Errors of measurement are caused by the same reasons as that in the experiments using the box.

\section{Discussion and conclusions}

Experiments on the hydrate dissociation in a two dimensional organic glass box and a one dimensional cylinder are carried out. It is shown that when hydrate is dissociated fast while the permeability of

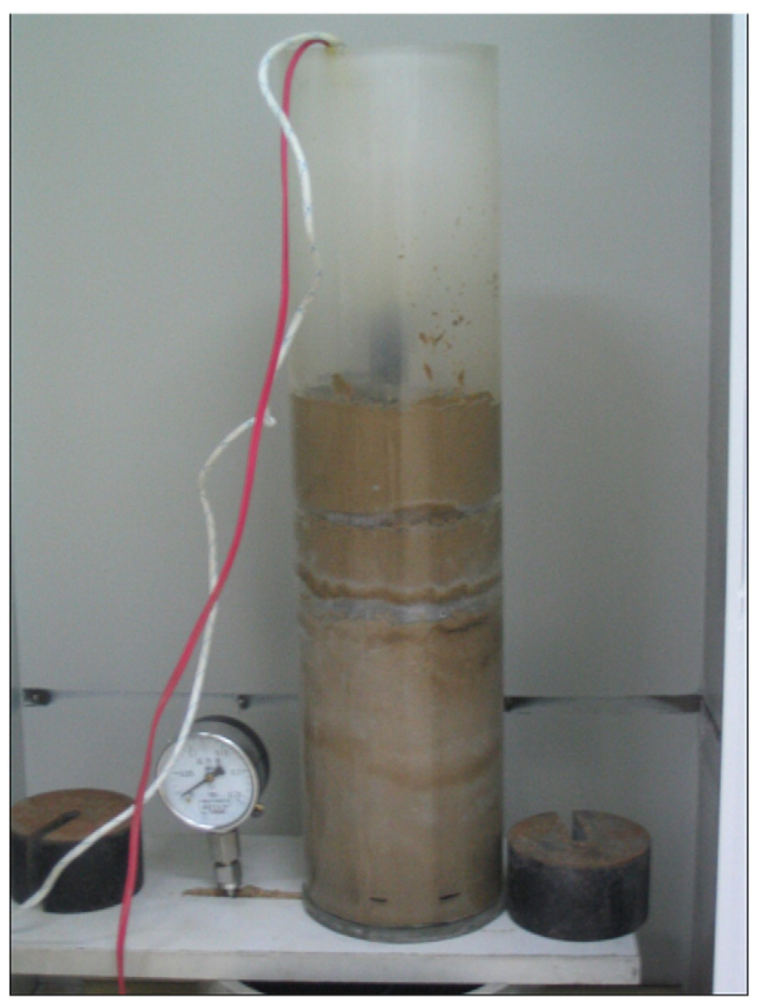

Fig. 8. Layered fracture. 


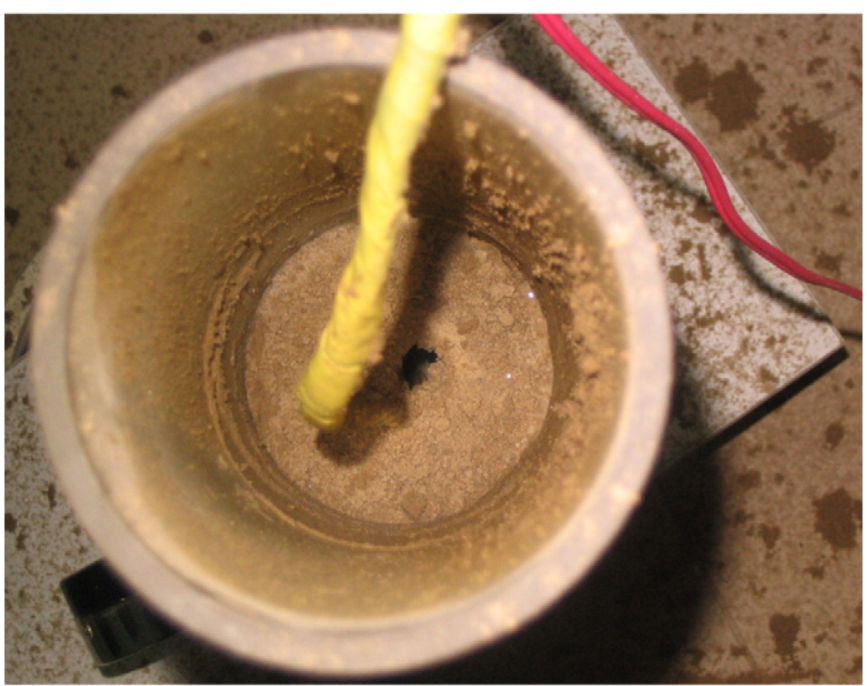

Fig. 9. After burst of soils.

HD is low, high gas pressure occurs in HD and leads liquefaction or even gasification of deposit in the dissociation zone. As a result, layered fracture or outburst may appear in weak positions.

Now a simple analysis is presented considering the critical failure status during hydrate dissociation in sediments. According to parameters in Table 3, critical damage condition can be expressed as follows:

$f\left(h, R, \tau_{f}, p_{g}, \bar{\rho} g, p_{0}\right)=0$.

Choose $\bar{\rho} g$ and $h$ as units, Eq. (1) can be written as dimensionless expression:

$f\left(\frac{R}{h}, \frac{p_{g}-p_{0}}{\bar{\rho} g h}, \frac{\tau_{f}}{\bar{\rho} g h}\right)=0$.

In which, $\frac{R}{h}$ is comparable critical failure size during hydrate dissociation, $\frac{p_{g}-p_{0}}{\bar{\rho} g h}$ is comparable excess pore pressure, $\frac{\tau_{f}}{\bar{\rho} g h}$ is comparable strength of hydrate-bearing sediments.

If comparable excess pore pressure exceeds comparable strength of hydrate-bearing sediments, i.e. $\frac{p_{g}-p_{0}}{\bar{\rho} g h}>f\left(\frac{R}{h}, \frac{\tau_{f}}{\bar{\rho} g h}\right)$, failure of hydratebearing sediments will occur.

In our experiments, when liquefiable or gasified soil sediment is overlain by less permeable layer, the over-layer can restrict the pore water or gas to pass through. With the expansion of the dissociation front, the over-layer will be pushed away or even destroyed once the comparable excess pore pressure $\frac{p_{g}-p_{0}}{\bar{\rho} g h}$ exceeds much of the effects of the comparable strength (gravity of over-layer and boundary friction $f\left(\frac{R}{h}, \frac{\tau_{f}}{\bar{\rho} g h}\right)$, which leads to a sudden unloading of pore pressure at the interface between the saturated or gasified sediment and the over-layer. Accordingly, an unloading wave will transmit into the

Table 3

Dimensionless analysis of stratum damage after hydrate dissociation.

\begin{tabular}{lll}
\hline Physical variables & Sign & Dimension \\
\hline Specific gravity & $\bar{\rho} g$ & {$[\bar{\rho} g]=M^{1} L^{-1} T^{-2}$} \\
Height & $h$ & {$\left[h_{s}\right]=M^{0} L^{1} T^{0}$} \\
Damage strength & $\tau_{f}$ & {$\left[\tau_{f}\right]=M^{1} L^{-1} T^{-2}$} \\
Critical dissociation length & $R$ & {$[R]=M^{0} L^{1} T^{0}$} \\
Gas pressure in sediments & $p_{g}$ & {$\left[p_{g}\right]=M^{1} L^{-1} T^{-2}$} \\
Atmosphere pressure & $p_{0}$ & {$\left[p_{0}\right]=M^{1} L^{-1} T^{-2}$} \\
\hline
\end{tabular}

sediment. At some places the sediment is fractured in layered form when the excess pressure is not too high; otherwise the fracture failure becomes continuous and the outburst failure occurs (Lu et al., 2006; Yu et al., 1997).

In addition, there exist critical pressures corresponding to the layer fracture failure and outburst failure. The critical value is closely related to the strength of sediments and the boundary friction. In the one dimension experiments of this paper, the critical gas pressure is $0.1 \mathrm{MPa}$ when layered fracture appears and it is $0.3 \mathrm{MPa}$ when outburst occurs. In the two dimension experiments, the critical gas pressure is $0.1 \mathrm{MPa}$. The relation $f\left(\frac{R}{h}, \frac{p_{g}-p_{0}}{\bar{\rho} g h}, \frac{\tau_{f}}{\bar{\rho} g h}\right)=0$ is being investigated.

\section{Acknowledgements}

This study is supported by the National High Technology Research and Development Program of China (863) and the Key Program of Chinese Academy of Sciences "KJCX2-YW-L02", Important National Science \& Technology Specific Projects "2008ZX05026-010" and the National Science Foundation (No. 1077218).

\section{References}

Bard, E., et al., 1990. Calibration of the $\mathrm{C}-14$ timescale over the past 30, 000 years using mass-spectrometric U-TH ages from barbados corals. Nature 345, 405-410.

Bouriak, S., et al., 2000. Inferred gas hydrates and clay diapirs near the Storegga Slide on the southern edge of the Voring Plateau, offshore Norway. Mar. Geol. 163 (1-4), 125-148.

Briaud, J.L., Chaouch, A.J., 1997. Hydrate melting in hydrate soil around hot conductor J. Geotech. Geoenir. Eng. 123 (7), 645-653.

Bugge, T., et al., 1987. A giant 3-stage submarine slide off Norway. Geo-Mar. Lett. 7, 191-198.

Dickens, G.R., Quinby-Hunt, M.S., 1994. Methane hydrate stability in seawater. Geophys. Res. Lett. 21 (19), 2115-2118.

Driscoll, N.W., et al., 2000. Potential for large scale submarine slope failure and tsunami generation along the US mid-Atlantic coast. Geology 28 (5), 407-410.

Gilles, G., et al., 1999. Characterization of in-situ elastic properties of gas hydate bearing sediments on the Blake Ridge. J. Geophys. Res. 104 (B8), 17781-17795.

Gruy, H.J., 1998. Natural gas hydrates and the mystery of the Bermuda Triangle. Hart's Pet. Eng. Int. 71 (3), 71-79.

Hisashi, O.K., et al., 2002. Synthesis of methane gas hydrate in porous sediments and its dissociation by depressurizing. Powder Tech. 122, 239-246.

Jones, K.W., et al., 2007. Microstructure of natural hydrate host sediments. Nucl. Instrum. Methods Phys. Res. B 261, 504-507.

Jung, W.Y., Peter, R.V., 2004. Effects of bottom water warming and sea level rise on Holocene hydrate dissociation and mass wasting along the Norwegian-Barents Continental Margin. J. Geophys. Res. 109 (B6), B06104.

Koh, C.A., 2002. Towards a fundamental understanding of natural gas hydrates. Chem. Soc. Rev. 31, 157.

Kvenvolden, K.A., 1998. Methane hydate-a major reservoir of carbon in the shallow geosphere. Chem. Geol. 71, 41-51.

Kwon, T.H., Cho, G.C., Santamarina, J.C., 2008. Gas hydrate dissociation in sediments: pressure-temperature evolution. Geochem. Geophys. Geosyst. 9, Q03019. doi:10.1029/ 2007GC001920.

Lu, X.B., et al., 2006. Formation mechanism of cracks in saturated sand. Acta Mech. Sin. $22,377-383$.

Milkov, A.V., 2000. Worldwide distribution of submarine mud volcanoes and associated gas hydrates. Mar. Geol. 167, 29-42.

Riedel, M., et al., 2006. Amplitude and frequency anomalies in regional 3D seismic data surrounding the Mallik 5L-38 research site, Mackenzie Delta, Northwest Territories, Canada. Geophysics 71 (6), B183-B191.

Sloan, E.D., 1998. Clathrate Hydrates of Natural Gases. Marcel Dekker Inc., New York.

Sultan, N., et al., 2004a. Dynamics of gas hydrate: case of Congo continental slope. Mar. Geol. 206, 1-18.

Sultan, N., et al., 2004b. Effect of gas hydrates melting on seafloor slope instability. Mar. Geol. 213, 379-401.

Tohidi, B., et al., 2001. Visual observation of gas hydrate formation and dissociation in synthetic porous media by means of glass micromodels. Geology 29 (9), 867-870.

$\mathrm{Xu}, \mathrm{W} ., \mathrm{Germanovich,} \mathrm{L.N.,} \mathrm{2006.} \mathrm{Excess} \mathrm{pore} \mathrm{pressure} \mathrm{resulting} \mathrm{from} \mathrm{methane} \mathrm{hydrate}$ dissociation in marine sediments: a theoretical approach. J. Geophys. Res. 111, B011104. doi:10.1029/2004JB003600

Xu, W., Germanovich, L.N., 2007. Reply to comment by Nabil Sultan on "Excess pore pressure sesulting from methane hydrate dissociation in marine sediments: a theoretical approach". J. Geophys. Res. 112, B02104. doi:10.1029/2006JB004722.

Yu, S.B., et al., 1997. Damage of porous media containing pressurized gas by unloading and the maximum damage principle for critical outburst. Acta Mech. Sin. 29 (6), 641-646 (in Chinese).

Zhang, X.H., Lu, X.B., Li, Q.P., Yao, H.Y., 2010. Thermally induced evolution of phase transformations in gas hydrate sediment. Sci. Chin. Phys. Mech. Astron. 53 (8), 1-6. doi:10.1007/s11433-010-4060-8. 